\title{
TrypanoCyc - a metabolic pathway database for Trypanosoma brucei
}

\author{
Bridget Chukualim*1, Nick Peters², Christiane Hertz Fowler ${ }^{2}$ and \\ Matthew Berriman ${ }^{2}$
}

\author{
Address: ${ }^{1}$ International Trypanotolerance Centre, Kerr Serign, Banjul, The Gambia and ${ }^{2}$ Wellcome Trust Sanger Institute, Cambridge, CB10 1 SA, \\ UK \\ Email: Bridget Chukualim* - bchukualim@yahoo.com \\ * Corresponding author
}

\author{
from Fourth International Society for Computational Biology (ISCB) Student Council Symposium \\ Toronto, Canada. 18 July 2008 \\ Published: 30 October 2008 \\ BMC Bioinformatics 2008, 9(Suppl I0):P5 doi:10.1186/I47I-2105-9-SI0-P5
}

This abstract is available from: http://www.biomedcentral.com/I47I-2/05/9/SI0/P5

(C) 2008 Chukualim et al; licensee BioMed Central Ltd

\section{Background}

Trypanosoma brucei (T. brucei) is a single celled parasite, subspecies of which are causative agents of African sleeping sickness in humans and nagana in domestic animals. Sleeping sickness is endemic in about 36 countries in SubSaharan Africa and is threatening over 60 million people. Disease prevention is a priority, as few effective drugs are available. Currently, there are only four drugs used as treatment: Pentamidine, Suramin. Melarsoprol and Eflornithine, though they have poor safety profiles, challenging treatment regimes and lack in efficacy. There is therefore a great need in identifying novel therapeutics for the treatment of sleeping sickness and fortunately, efforts have intensified over recent years. One such development has been the availability of the Pathway Tools Software [1]. We have used this production software to set up TrypanoCyc, a metabolic pathway database for T. brucei http://www.genedb.org/tmp/.

\section{Methods/results}

Based on the available genome annotation, Pathologic assigned proteins to reactions and pathways. The Pathway hole filler algorithm was subsequently used to identify missing enzyme annotations in the T. brucei genome. Further manual refinement included enzymes and pathways previously identified in the literature but unique to T. brucei (e.g. GPI Biosynthetic pathway) and thus not present as 'generic' pathways in the tool. A total of 178 pathways were identified comprising 1112 enzymes, 341 of which represented additional annotations to proteins with no previous functional assignments.

In order to determine potential drug targets, we performed chokepoint analyses of the metabolic network of T. brucei. We define a "chokepoint reaction" as a reaction that either uniquely consumes a specific substrate or uniquely produces a specific product in the TrypanoCyc metabolic network. We expect the inhibition of an enzyme that consumes a unique substrate to result in the accumulation of the unique substrate (potentially toxic to the cell) and the inhibition of an enzyme that produces a unique product to result in the starvation of the unique product (potentially crippling essential cell functions).

168 enzymes were identified as choke point enzymes and this set included almost all of the drug targets of currently used and proposed drugs (e.g. trypanothione pathway Figure 1) against sleeping sickness.

\section{Conclusion}

TrypanoCyc, a database of metabolic pathways for T. brucei will remain an invaluable resource for detailed analyses of the metabolic network of the parasite T. brucei and related species. The database will continually be updated with new reactions and pathways identified from Litera- 


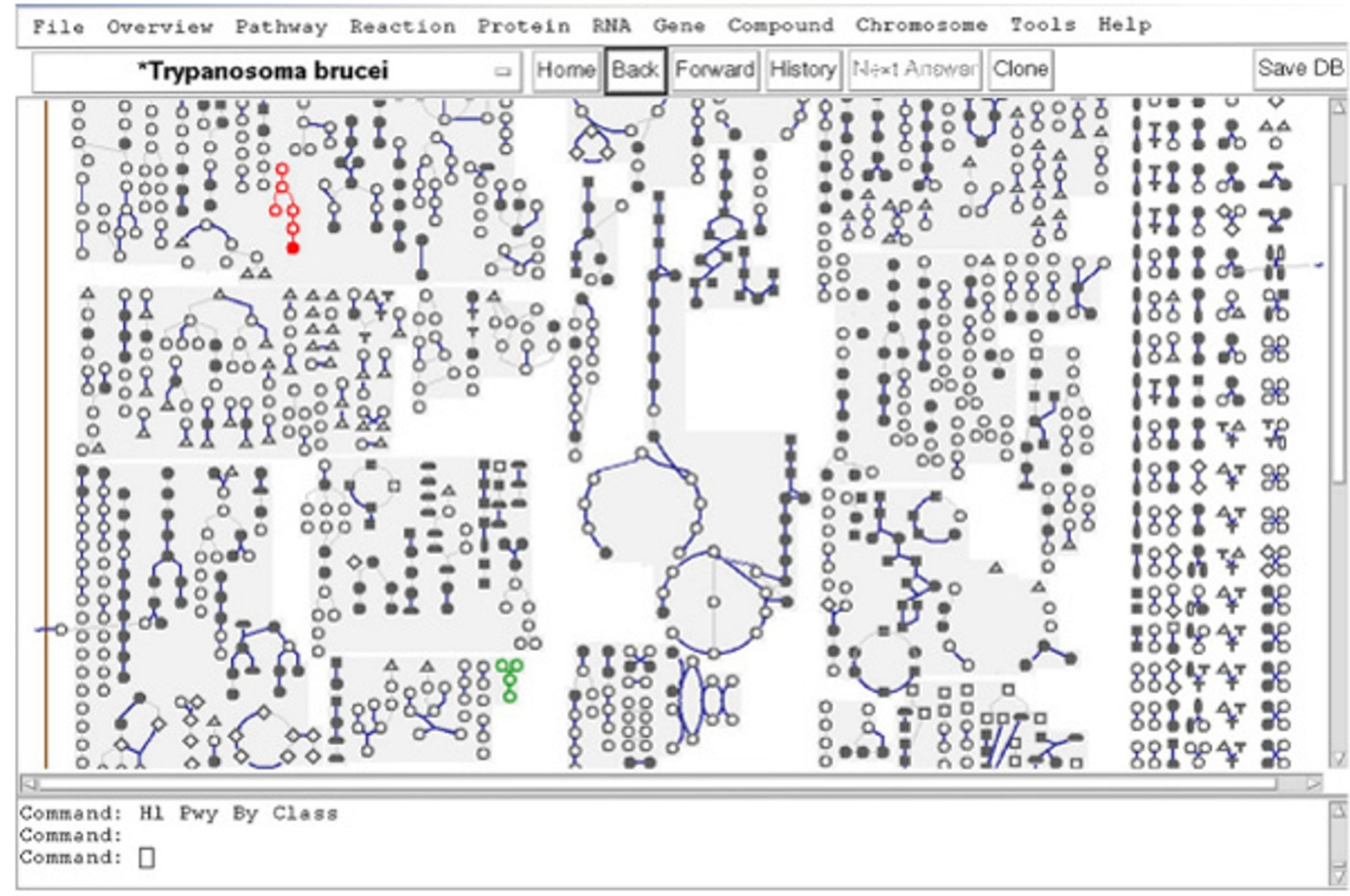

Figure I

A graphical overview of TrypanoCyc: Trypanothione pathway (coloured green) and biopterin pathway (coloured red) in graphical overview diagram of TrypanoCyc.

ture and refinement of chokepoint analyses to identify potential drug targets would be a priority.

\section{References}

I. Karp P, Paley S, Romero P: The Pathway Tools software. Bioinformatics 2002, I8(I):S225-S2232.

\begin{tabular}{|l|}
\hline Publish with BioMed Central and every \\
scientist can read your work free of charge \\
"BioMed Central will be the most significant development for \\
disseminating the results of biomedical research in our lifetime. " \\
Sir Paul Nurse, Cancer Research UK \\
Your research papers will be: \\
• available free of charge to the entire biomedical community \\
• peer reviewed and published immediately upon acceptance \\
• cited in PubMed and archived on PubMed Central \\
• yours - you keep the copyright \\
Submit your manuscript here: \\
http://www.biomedcentral.com/info/publishing_adv.asp
\end{tabular}

